\title{
COVID-19 Pandemi Sürecinde, Türk Üniversitelerinin Hizmet Kalite Düzeylerini Belirlemeye Yönelik Bir Araştırma
}

DOI: $10.26466 /$ opus. 944561

\author{
Alpaslan Alpaslanoğlu* \\ * Dr. Öğretim Üyesi, Iğdır Üniversitesi, İktisadi ve İdari Bilimler Fakültesi, Iğdır/Türkiye \\ E-Posta: aalpaslanoglu@gmail.com \\ ORCID: $0000-0003-0859-984 \mathrm{X}$
}

Öz

COVID-19 Pandemi döneminde yapılan araştırmada, Pandemi döneminin hizmet algısına etkisinin kaçınılmaz olabileceği düşüncesi ile çalışmanın önemli bir mihenk taşı olabileceğgi düşünülmektedir. Öte yandan literatürde tekil olmayan, kapsayıcı nitelikte üniversite hizmet kalitesini belirlemeye yönelik araştırmaların olmayışı, COVID-19 Pandemi döneminin dikkate alınması da diğer önemli görülebilecek hususlardandır. Araştırma, Devlet veya Vakıf Üniversitelerinde okuyan ya da mezunu olan 494 katılımo ile Türk Üniversitelerinin hizmet kalitelerini belirlemeye yönelik olarak yapılmış, birincil tür verilerle ve kantitatif yönetemlerle tümevarmsal bulgular elde etmek üzere gerçekleştirilmiştir. Hizmet kalitesi, bu maksatla kullanılan en önemli ve kabul gören ölçeklerden birisi olan SERVQUAL yöntemi ve ölçeği ile ölçümlenmiş, istatistik analizlerle bulgulara erişilmiş ve sonuçlandırılmıştır. Araştırma bulgularına göre, hem Devlet hem de Vakıf Üniversitelerinin, COVID19 Pandemi döneminde SERVQUAL ölçeğinde belirtilen 22 adet konunun tamaminda memnuniyet oluşturamadıkları gözlemlenmiştir. En yüksek memnuniyetsizlik konularının; "teknolojik donanım eksikliği", "eğitim hizmetlerine duyulan güven" ile "çalışanlarm nitelik ve nicelikleri" ile ilgili olduğu gözlemlenmiştir. Vakıf Üniversiteleri için "eğitim hizmetlerine duyulan güven" konusu en büyük memnuniyetsizlik konusu iken Devlet Üniversiteleri için "teknolojik donanım eksikliği" olduğu bulgulanmıştır. "Güvence", "Güvenirlik" ve "Empati" faktörleri en fazla memnuniyetsizlik oluşturan parametreler olarak gözlemlenmişlerdir. Araştırmada kullanılan SERVQUAL ölçeğinin kullanılabilmesi için telif hakkı sahiplerinden kullanım izni alınmış ve Etik kurul uygunluğu alınmıştır.

Anahtar Kelimeler: Üniversite Hizmet Kalitesi, Türk Üniversiteleri Hizmet Kalitesi, Üniversite Ĕ̆itim Hizmetleri Halitesi, Devlet Ve Vakıf Üniversite Ĕ̆itim Hizmetleri Kalitesi, SERVQUAL Ölçeği Ile Üniversite Hizmet Kalitesi Ölçümü. 


\title{
A Research to Determine the Service Quality Levels of Turkish Universities in the COVID-19 Pandemic Process
}

\begin{abstract}
In the study conducted during the COVID-19 Pandemic period, it is thought that the study may be an important touchstone with the thought that the effect of the pandemic period on service perception may be inevitable. On the other hand, the lack of studies to determine the quality of university service in a non-singular and inclusive nature in the literature and the consideration of the COVID-19 Pandemic period are other important issues. The research was carried out to determine the service quality of Turkish Universities with 494 participants who are studying or graduated from State or Foundation Universities, and it was carried out to obtain inductive findings with primary type data and quantitative methods. Service quality was measured with the SERVQUAL method and scale, which is one of the most important and accepted scales used for this purpose, and the findings were reached and concluded with statistical analysis. According to the findings of the research, it was observed that both State and Foundation Universities were not able to create satisfaction in all 22 subjects specified on the SERVQUAL scale during the COVID-19 Pandemic period. The highest issues of dissatisfaction; It has been observed that it is related to "lack of technological equipment", "trust in education services" and "the quality and quantity of employees". While the issue of "trust in educational services" is the biggest dissatisfaction issue for Foundation Universities, it has been found that "lack of technological equipment" is for State Universities. "Assurance", "Reliability" and "Empathy" factors were observed as the parameters that created the most dissatisfaction. In order to use the SERVQUAL scale used in the study, permission to use was obtained from the copyright owners and the permission of the Ethics committee was requested.
\end{abstract}

Keywords: University Service Quality, Turkish Universities Service Quality, University Education Services State, State And Foundation University Education Services Quality, University Service Quality Measurement With SERVQUAL Scale. 


\section{Giriş}

COVID-19 Pandemisi, insanlık medenyetini her alanında olduğu gibi, eğitim kurum ve yönetimlerini de zorlu testlere tabi tutmaktadır. Bu zorlu test dönemi içinde üniversite yönetimlerinin göstermiş oldukları performanslara ilişkin en önemli göstergelerden birisi de hizmet memnuniyet düzeyi ile paydaş beklentilerinin karşılanabilme düzeyi olduğu düşünülmektedir. Buradan hareketle, COVID-19 Pandemisi dönemi içinde gösterilmiş olan yönetim davranışlarının etkinliği araştırmanının problemini temsil ederken, pandemi sürecinde üniversite yönetimlerinin şu ana değin göstermiş oldukları yönetim davranışları sonucunda ortaya çıkan memnuniyet düzeyinin belirlenmesi ve optimal yönetim uygulamaları arayışı, bu araştırmanın amacını oluşturmaktadır.

Araştırmanın gerekçeleri; COVID-19 Pandemi dönemi içinde, örgüte yönelik beklentiler ile örgütsel varlıklardan hangilerinin daha önemli görüldüğü ve üniversite yönetimleri başta olmak üzere, tüm alanlarda; COVID-19 Pandemi döneminde daha etkin yönetim davranışlarının gösterilip gösterilemedeğine ilişkin cevap arayışlarıdır.

Araştırma bulgularının; COVID19 Pandemi dönemi, dönem sonrası ve olağanüstü ya da öngörülemez durumlarda daha etkin yönetim davranışlarının geliştirilebilmesi için önemli olabileceği düşünülmektedir. Öte yandan benzer yöntemlerle diğer alan ve sektörlerden edilebilecek değerler ile COVID-19 Pandemi süreci için yönetim davranışları karşılaştırmaları ve neticesinde daha etkin uygulamaların ortaya konulabileceği de düşünülmektedir. Öte yandan insanlık tarihinin istisnai bir zaman dilimi olarak kabul edilebilecek COVID19 Pandemi döneminde, üniversite hizmet kalite seviyesini belirlemeye yönelik olarak, mihenk taşı olabilecek nitelikte bir araştırma olabileceği beklentisi nedeni ile de önemli görülmektedir.

\section{Kavramsal Çerçeve}

Yüksek kaliteli araştırma ve eğitim, toplumlar için son derece gereklidir ve toplumunun ihtiyaç duyduğu yeniliklerin sadece bunu sağlayanlarca değil, herkes tarafından yapılması için, her yerde desteklenmeleri gerekmektedir (Marinoni, Land ve Jensen, 2020). COVID-19 Pandemi krizi, 
yüksek öğretim kurumlarına birçok bakımdan yeni ve beklenmedik şekilde etkilerde bulunmuştur (International Association of Universities, 2021). Bu nedenle üniversiteler, salgına karşı radikal önlemler almak ve büyük çabalar sarf etmek zorunda kalırken, kriz yönetiminde yeni yollar aramaktadırlar. Özellikle dijitalleşme ve dijital tabanlı öğrenim, açık bilim ve araştırma, kalite güvencesi, üniversite özerkliği, finansman ve sivil katılım ile ilgili konularda, üniversiteler için hem zorlukların hem de fırsatların söz konusu olduğu (European University Association, 2021) ifade edilebilir. Dolayısıyla, süreç içinde öne çıkan bu konular içinde eğitim kalitesinin hem bir girdi hem de bir sonuç olması nedeni ile dikkat çekici olduğu ifade edilebilir. Uluslararası Üniversiteler Birliği tarafından küresel ölçekte yapılan kapsamlı bir araştırmaya göre; özellikle COVID-19 döneminde öne çıkan dijital tabanlı uzaktan eğitim odaklı üniversite eğitim kalitesi ile ilgili eğitimin fizibilitesini ve kalitesini etkileyen birbiriyle bağlantılı birkaç boyut ortaya konulmuştur, söz konusu boyutlar: "Teknik altyapı ve erişilebilirlik", "uzaktan eğitim yeterlilikleri ve pedagojileri" ile "çalışma alanları" olarak ifade edilmiştir (Marinoni, Land ve Jensen, 2020).

Hizmet, sıklıkla faydalı bir faaliyet olarak tanımlanabilir. Faydalı bir faaliyet olarak kabul edilen bir hizmetin aslında uzun bir geçmişi vardır (Qiu, 2014, s.1). Hizmet; tüketicileri için yarar sağlaması amacı ile insan çabası sonucunda, insan ve/veya makina aracılı̆̆ ile üretilen, fiziksel nitelikte olmayan ürünler (Skinner, 1990, s.631) biçiminde açıklanabilir. Ayrıca, satışa sunulan, esasen soyut olan ve hiçbir şeye sahip olmakla sonuçlanmayan faaliyetler, faydalar veya tatminlerden oluşan bir ürün biçimi (Armstrong, Kotler, Trifts ve Buchwitz, 2017, s.278) olarak da ifade edilebilir. Hizmete ilişkin dört ayırt edici özellikten bahsedilebilir, bunlar: soyutluk, ayrılmazlık, değişkenlik ve çabuk bozulabilirlik (Kotler ve Armstrong, 2018, s.258) nitelikleridir.

Hizmet için en önemli hususların başında, "hizmet kalitesi" gelmektedir. Genellikle, hizmetin üretilmesinden çok hizmet kalitesi daha önemli olabilmektedir. Aslında hizmetin kalitesi daha çok, tüketicleri tarafından verilen bir derecelendirmeden ibarettir. Çünkü, hizmet kalitesi, tüketici beklentilerinin sunulan hizmet tarafından karşılanma derecesi (Bitner ve Hubbert, 1994) olarak açıklanmaktadır. 
Kalitenin tanımı kısadır, ancak doğası gereği biraz tekniktir ve günlük kullanım için yeteri kadar basit değildir. Çünkü kalite ile ilgili terimler grubunda, "müşteri memnuniyeti" ve "gereksinimler" yer almaktadır ve bu kavramlar geniş yelpaze içinde değişkenlik gösterebilmektedir. Öte yandan kalite; ihtiyaçların ve beklentilerin ötesine geçerek, ima edilen ihtiyaç ve beklentilerin karşılanabilmesini içerir (QualityWBT Center for Education, 2017) ki bu durum, hem kavramsal hem de pratik çerçevede kalite kavramına ilişkin bazı güçlükleri ortaya çıkartabilmektedir. Çünkü, bir ürün veya hizmetin kalitesi; biri ürün veya hizmeti sağlayan, diğeri ürün veya hizmeti alan iki taraf arasındaki değiş tokuşa bağlıdır. Tedarikçi ve müşteri, kalitenin ne olduğu konusunda farklı görüşlere sahip olabilir ve bu, yanlış anlaşılmalara ve anlaşmazlıklara yol açabilir. Bu doğrultuda kalite, "müşterilerin gereksinimlerine uygunluk veya amaca uygunluk" olarak da ifade edilebilir (International Trade Centre, 2011, s.7). Dolayısıyla kalitenin; ürünün tüketici beklentilerine göre uygunluk düzeyi olduğu söylenebilir. Önemli olan yönetimin değil, müşterinin kalite algısıdır ve bu açıdan hizmet kalitesinin yegane belirleyicisi, tüketicilerdir (Berry, Parasuraman ve Zeithaml, 1988). Bu durumda, müşteriyi elde tutma, belki de en iyi kalite ölçüsüdür; bir hizmet üreticisinin müşterilerine bağlı kalma yeteneği, onlara ne kadar tutarlı bir şekilde değer kattığına bağlıdır (Kotler, Armstrong, Harris ve He, 2020, s.250). Öte yandan "kalite" terimi göreceli bir anlama da sahiptir. "Bir ürün veya hizmetin belirtilen veya ima edilen ihtiyaçları karşılama kabiliyetine dayanan özellik ve özelliklerinin toplamıdır" (Food and Agriculture Organization of the United Nations, t.y.). Bir başka fade ile, bir ürünün "tüketicinin belirttiği gereksinimleri karşıladığında" iyi bir kaliteye sahip olduğu söylenebilir. Öte yandan Deming, kalitenin dinamik yönüne vurgu yaparak, kalitenin "müşterinin şimdiki ve gelecekteki ihtiyaçlarına yönelik olması" (Fonseca, Amaral ve Oliveira, 2021) gerektiğini belirtmiştir. Buraya kadar verilen bilgiler ışığında, en genel tanımı itibari ile kalitenin; "tüketicilerin ürün ya da hizmet ile ilgili yargıları" (Deming, 2019, s.137) ya da bir ürün veya hizmetin belirtilen veya ima edilen ihtiyaçları karşılama kabiliyetine dayanan özellik ve özelliklerinin toplamı (Organisation for Economic Cooperation and Development. Glossary of statistical terms, 2006) olarak ifade edilebilir. Bir organizasyon için kabul edilebilir bir kalite düzeyi 
olarak nitelendirilen husus; sonuçta paydaşlara yönelik bir sorudur. Söz konusu paydaşlar, kuruluşun yaptığı şeyin başarısıyla ilgilenen herkesi kapsamaktadır (Chartered Quality Professional ve International Register of Certificated Auditors, 2021). Kalitenin beklenen yararları şunlardır (American Society for Quality, t.y.):

- Güçlendirilmiş rekabet konumu,

- Değişen veya yükselen piyasa koşullar ile çevresel ve diğer yasal düzenlemelere uyarlanabilirlik,

- Daha yüksek üretkenlik,

- Geliştirilmiş pazar imajı,

- Hataların ve israfın giderilmesi,

- Daha düşük maliyetler ve daha iyi maliyet yönetimi,

- Daha yüksek karlılık,

- İyileştirilmiş müşteri odaklılık ve memnuniyet,

- Artan müşteri sadakati ve elde tutma,

- Artan iş güvenliği,

- Çalışan moralinin artması,

- Hissedar ve paydaş değerinin artması,

- İyileştirilmiş ve yenilikçi süreçler,

\section{Yöntem}

COVID-19 Pandemi döneminde üniversite yönetimlerinin etkinliğinde hizmet kalite düzeyine odaklanmış olan bu araştırma; kantitatif nitelikte, birincil tür verilerden yararlanılarak, istatsitiksel analizler aracılığ 1 ile tümevarımsal sonuçlar elde etmek üzere yapılmıştır. Tesadüfi örneklem ile 494 katılımcıdan elde edilen veri setinin oluşturulma dönemi 26.12.2020 ile 25.04.2021 tarihleri arasındadır. Söz konusu soru formları, çeşitli sosyal medya ve internet tabanlı iletişim mecraları üzerinden, yükseköğrenimini tamamlamış ya da devam etmekte olan ilgililere sunulmuştur. Araştırmanın evreni üniversiteler iken örneklemi ise Türkiye'de yerleşik olan Devlet ve Vakıf statüsündeki üniversitelerdir.

Araştırmada, hizmet kalitesini ölçmek üzere literatürün en öne çıan ölçeklerinden olan SERVQUAL hizmet kalitesi ölçeği (Kotler ve Keller, 2016, s.684; Parasuraman, Zeithaml ve Berry, 1994a), Türkçeye çevrilerek kullanılmıştır. Geniş bir hizmet yelpazesinde uygulanabilen SERV- 
QUAL, geçerlilik ve güvenilirliği iyi düzeyde sağlayabilen bir ölçektir (Parasuraman, Berry ve Zeithaml, 1991).

Ölçek soruları 5 basamaklı Likert derecelendirmesine sahiptir (1 en düşük, 5 en yüksek). 5 adet faktör ve 22 adet soru ifadesine sahip olan SERVQUAL ölçeği; bir seti algılanan hizmet kalitesi ile aynı ifadelerle beklenen hizmet kalitesini ölçen bir başka set olmak üzere iki set halinde ölçümler yapmaktadır. Ölçüm işlemi, algılanan hizmet kalite derecesi ile beklenen hizmet kalite derecesinin karşılaştırılmasına dayanmaktadır (Parasuraman, Zeithaml ve Berry, 1985). Karşılaştırma sonucunda; algilanan hizmet, beklenen hizmet seviyesinin üzerinde ise memnuniyet, altında bir değerde ise de memnuniyetsizlik durumunun oluştuğunu göstermektedir (Parasuraman, Zeithaml ve Berry, 1988). Çünkü, Parasuraman ve arkadaşlarına göre ise hizmet kalitesi; tüketicilerin herhangi bir hizmetten elde etmek istedikleri faydalar (beklenti) ile elde ettikleri değerler (algılar) arasındaki farklıktır (Parasuman vd., 1985; Parasuraman, Zeithaml, ve Berry, 1994b). Dolayısıyla çalışmada, hizmet kalite düzeyi bu yöntemle ve ölçekle belirlenmeye çalışılmıştır.

SERVQUAL ölçeğinin uygulanması neticesinde; Ölçeğin bütününe ilişkin Cronbach's Alpha güvenirlik düzeyi 0,851 değeri ile yüksek düzeyde güvenirlik düzeyine sahiptir. Ayrıca KMO değeri 0,952 $(p<0,05)$ mertebesinde hesaplanmış olup iç tutarlık katsayısı da üst düzeyde sağlanmakta, örnek hacminin yeterli düzeyde olduğunu ve verilerin normal dağılıma uygunluğunu göstermektedir (Güriş ve Astar, 2014, s.373). Ölçeğin her bir ifadesi ve faktörlerine ilişkin Cronbach's Alpha güvenirlik düzeylerinin de son derece yüksek düzeyde (Özdemir, 2019, s.323) olduğu ifade edilebilir (Tablo 1).

Tablo 1. Ölçeğe ilişkin güvenirlik ve geçerlilik analiz sonuçları

\begin{tabular}{|c|c|c|c|c|}
\hline \multirow{2}{*}{ Faktörler } & \multicolumn{2}{|c|}{ Cronbach's Alpha } & \multicolumn{2}{|c|}{ KMO $^{*}$} \\
\hline & Alg1 & Beklenti & Alg1 & Beklenti \\
\hline Fiziksel Ögeler & 0,823 & 0,765 & & \\
\hline Güvenirlik & 0,894 & 0,834 & & \\
\hline Duyarlılık & 0,902 & 0,865 & 0,965 & 0,957 \\
\hline Güvence & 0,920 & 0,902 & & \\
\hline Empati & 0,905 & 0,843 & & \\
\hline
\end{tabular}

${ }^{*} P<0,05$ 
SERVQUAL Ölçeğinin 5 boyutuna ilişkin kısa tanımlar aşağıda sıralanmıştır (Parasuraman vd., 1988; Zeithaml, Berry ve Parasuraman, 1996):

- Fiziksel Ögeler (Tangibles): Fiziksel tesisler, ekipman ve personelin görünümü,

- Güvenilirlik (Reliability): Vaat edilen hizmeti güvenilir ve doğru bir şekilde gerçekleştirme becerisi,

- Duyarlılık (Responsiveness): Tüketicilere yardım etme ve hızlı hizmet sunma istekliliği,

- Güvence (Assurance): Çalışanların bilgisi ve nezaketi ile güven sağlama ve güven uyandırma yetenekleri,

- Empati (Empathy): Kuruluşun tüketicilerine sunduğu özenli, kişiselleştirilmiş ilgi.

Araştırmada kullanılan SERVQUAL ölçeğinin kullanılabilmesi için telif hakkı sahiplerinden kullanım izni alınmış ve Etik kurul uygunluk raporu alınmıştır. Öte yandan, bu çalışma ile ilgili doğrudan ya da dolaylı herhangi bir çıkar çatışması bulunmamakla beraber, destekleyici veya sponsor vs. gibi herhangi üçüncü taraf ya da ilgili mevcut değildir. $\mathrm{Bu}$ araştırma, bilimsel bulgular elde etmek üzere, bağımsız olarak gerçekleştirilmiştir.

\section{Bulgular}

Demografik bulgular:Araştırma katılımcılarının \%52 oranı kadınlardan, $\% 48$ oranı erkeklerden ve $\% 60$ oranı bekar, $\% 40$ oranı evli kişilerden oluşmaktadır. Araştırmaya katılanların yarıya yakını 21-30 yaş aralığındadır, yaş ilerledikçe katılım oranı düşmektedir (Tablo 2). Katılımcıların eğitim sevilerine göre; en büyük grubun lisans eğitimi olanlardan (\%67), en az katılımın ise doktora dereceli mezun ya da öğrencilerinden (\%15) olduğu, dolayısıyla \%67 oranında yükseköğrenim, \%33 oranında lisansüstü eğitim düzeyinde katılım gerçekleşmiştir (Tablo 3). 
Tablo 2. Katılımcıların yaş dağılımlarına ilişkin göstergeler

\begin{tabular}{llll}
\hline Yaş & Dağılım & Oran (\%) & Kümülatif oran (\%) \\
\hline $21-30$ & 243 & 49,2 & 49,2 \\
$31-40$ & 113 & 22,9 & 72,1 \\
$41-50$ & 75 & 15,2 & 87,2 \\
$51-60$ & 50 & 10,1 & 97,4 \\
61 ve üstü & 13 & 2,6 & 100,0 \\
Toplam & 494 & 100,0 & \\
\hline
\end{tabular}

Tablo 3. Katılımcıların eğitim durumlarına ilişkin göstergeler

\begin{tabular}{llll}
\hline Eğitim düzeyi & Dağılım & Oran (\%) & Kümülatif oran (\%) \\
\hline Ön lisans & 99 & 20,0 & 20,0 \\
Lisans & 231 & 46,8 & 66,8 \\
Yüksek Lisans & 89 & 18,0 & 84,8 \\
Doktora & 75 & 15,2 & 100,0 \\
Toplam & 494 & 100,0 & \\
\hline
\end{tabular}

Katılımcıların mezun olduğu/okuduğu ve değerlendirmede bulunduğu üniversitelerin yapılarına göre dağılımlarında \%84 oranında (416 adet) Devlet Üniversitesine karşın 78 adet Vakıf Üniversitesi olduğu tespit edilmiştir (Şekil 1).

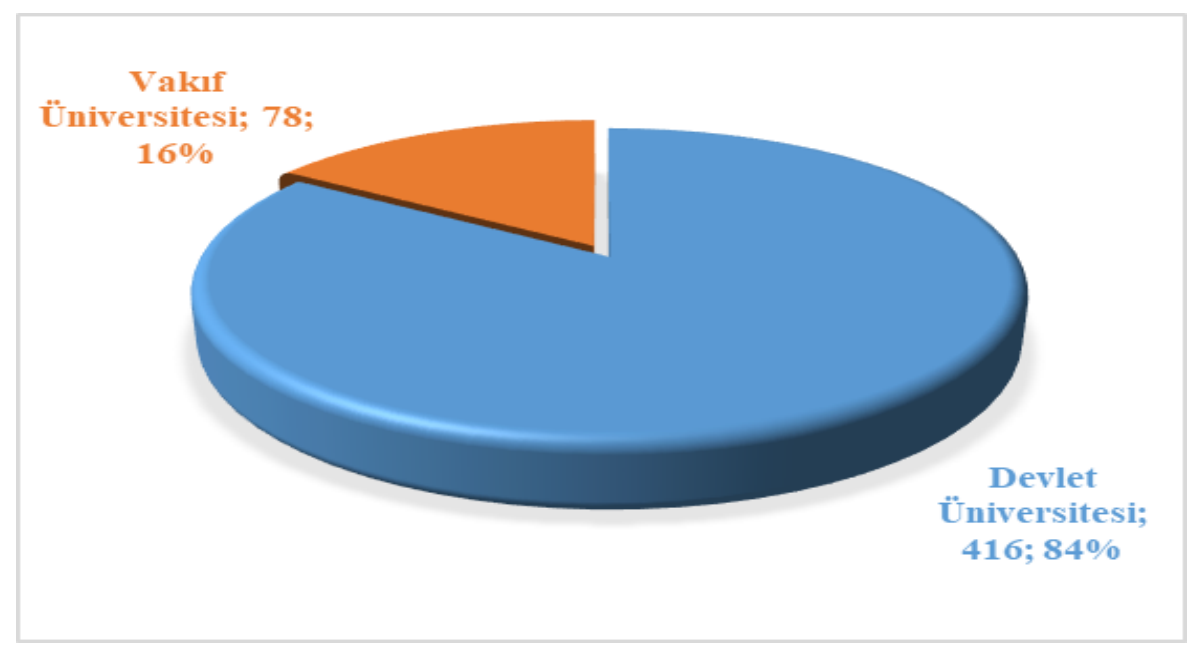

Şekil 1. Katılımcıların değerlendirmiş oldukları üniversitelerin yapılarına göre dağılımları 


\section{Üniversite Hizmet Kalitesine İlişkin Bulgular}

Araştırma sonucunda elde edilen en göze çarpan bulgu; hizmet kalite düzeyinin hem tüm soru ifadelerinde (22 adet soru) hem tüm faktörlerde (5 adet faktör) ve hem de genel SERVQUAL derecesinde negatif değerlerde gözlemlenmiş olmasıdır. Bu gözlem, hizmet kalite seviyesini belirleyen her bir öge için dikkat çekici düzeyde memnuniyetsizliğe işaret etmektedir. Algılanan hizmet kalite düzeyi 3,45, beklenen hizmet kalite düzeyi 4,51 seviyesinde gözlemlenirken, hizmetler genel memnuniyet düzeyi göstergesi olan SERVQUAL puanı ise $-1,06$ seviyesinde hesaplanmıştır (Tablo rr).

En yüksek düzeyde memnuniyetsizliğin; 4,51 beklentiye karşın, 3,11 alg1 derecesi ile -1,40 düzeyinde "Son teknolojiye uygun, yeni donanım kullanımı" konusunda olduğu gözlemlenmiştir (Şekil 2 ve Tablo 4).

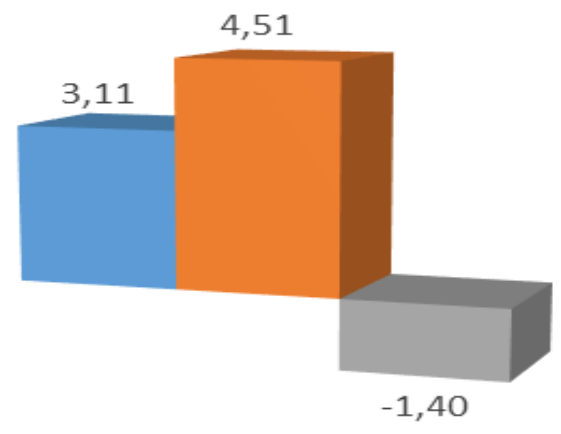

Şekil 2. "Son teknolojiye uygun, yeni donanım kullanımının" Algı, Beklenti ve SERVQUAL puanlarn

Öne çıkan diğer memnuniyetsizlik alanlarının ise; -1,27 düzeyinde “Üniversitede öğrencilerin, aldıkları eğitim hizmetlerine karşı güven duymaları", -0,121 düzeyinde "Üniversitede, tüm öğrencilerle ilgilenmeye yetecek sayıda çalışan bulunması" ve "Üniversite çalışanlarının, problem çözme konusunda samimi bir ilgi göstermeleri" biçiminde sıralandıkları gözlemlenmiştir (Tablo 4). 
Öte yandan memnuyetsizliğin en düşük olduğu hizmet ögelerinin; 0,73 düzeyinde "Binaların çağdaş bir görünüme sahip olması" ile "Üniversitede eğitim hizmetlerinin mümkün olan en kısa süre içerisinde sunulması", -0,84 değerle "Çalışanların temiz, düzgün ve tertipli bir görünüme sahip olması", -0,88 değerle "Eğitim hizmetlerinin, belirlenmiş zaman programlarına bağlı kalınarak düzenli bir şekilde sunulması" biçiminde sıralanmıştır (Tablo 4).

Faktörlere göre SERVQUAL puanlarının tamamının negatif değerlerde olduğu, ayrıca en düşük memnuniyetsizliğin, -1,16 değerle "Güvence", -1,06 değerle "Güvenirlik" ve "Empati" faktörlerinde, nispeten en az memnuniyetsizliğin ise $-0,97$ değerle "Duyarlılık" faktöründe ortaya çıkmış olduğu gözlemlenmiştir (Tablo 5). En yüksek dereceden beklentiler "Güvence" ile ilgili konularda, en düşük dereceden beklentiler ise "Fiziksel Ögeler" ile ilgili konularda oluşmuştur. Buna karşın, nispeten en düşük dereceli algılar "Fiziksel Ögeler" ile ilgili konularda olurken en yüksek dereceli algılar "Duyarlılık" ile ilgili konularda ortaya çıkmıştır (Şekil 3). Söz konusu değerlerin, 100'lük basamaklara dönüştürülerek ifade edildiği Şekil 4'de durum, daha net görülebilmektedir. 
Tablo 4. Algı, Beklenti ve SERVQUAL puanlarının ifadelere göre dağılımı

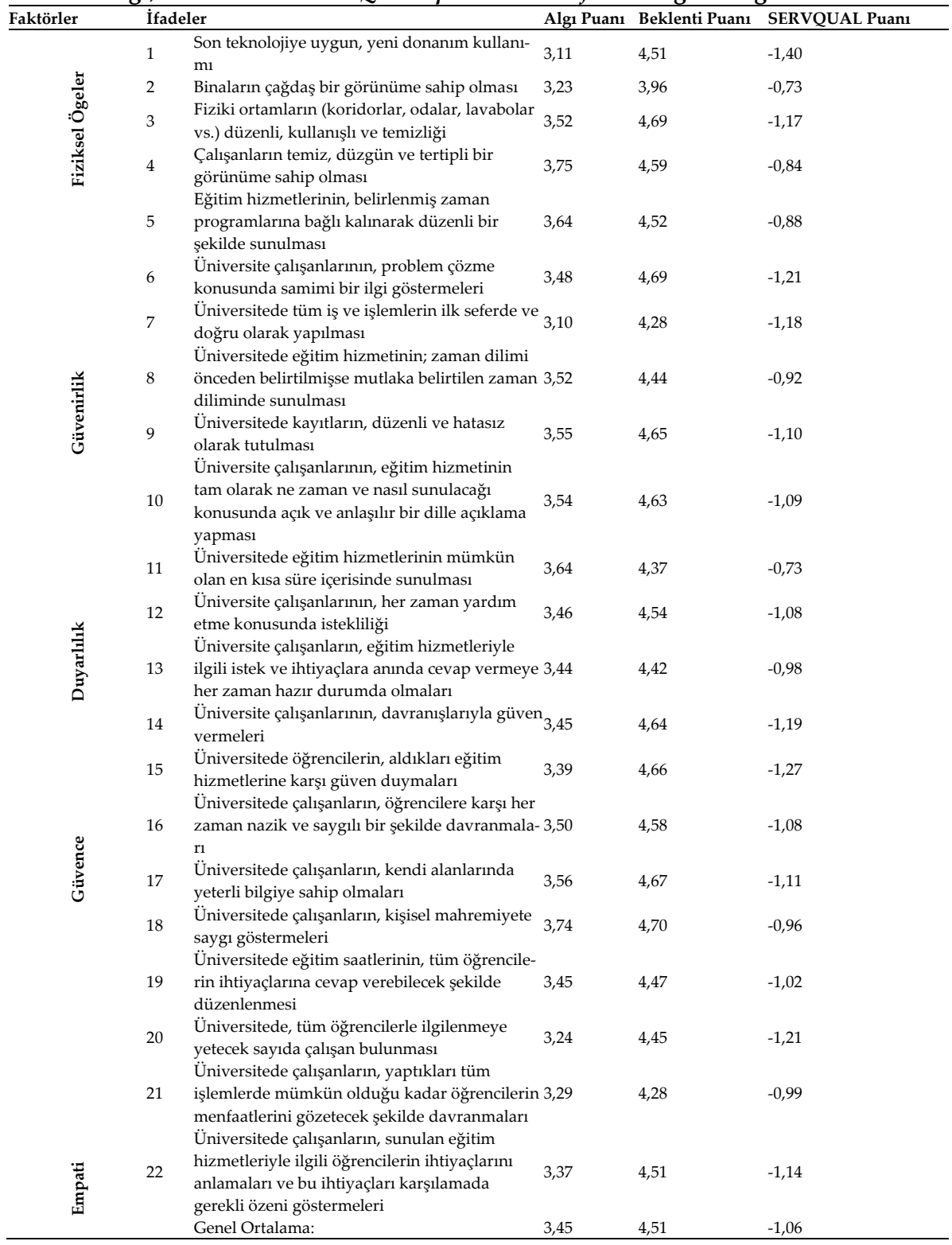


Tablo 5. Algı, Beklenti ve SERVQUAL puanlarının faktörlere göre dağılımı

\begin{tabular}{llll}
\hline Faktörler & Algı Puanı & Beklenti Puanı & SERVQUAL Puanı \\
\hline Fiziksel Ögeler & 3,40 & 4,44 & $-1,04$ \\
Güvenirlik & 3,46 & 4,52 & $-1,06$ \\
Duyarll1ık & 3,52 & 4,49 & $-0,97$ \\
Güvence & 3,48 & 4,64 & $-1,16$ \\
Empati & 3,42 & 4,48 & $-1,06$ \\
Genel puan: & 3,46 & 4,51 & $-1,06$ \\
\hline
\end{tabular}

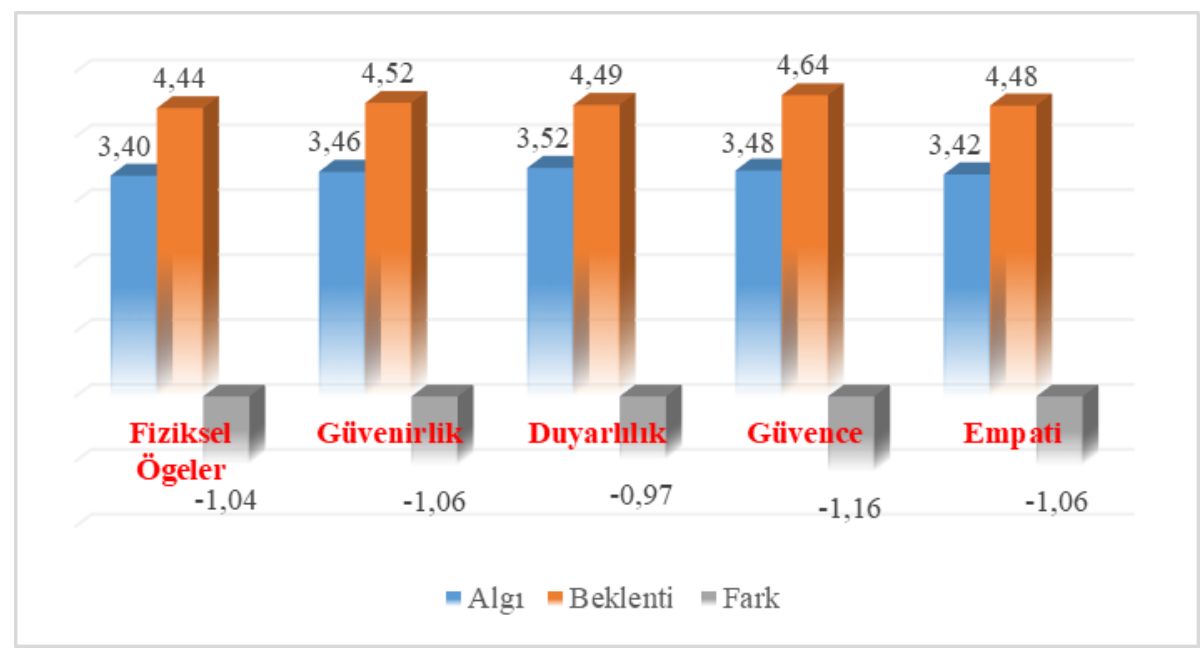

Şekil 3. Algı, Beklenti ve SERVQUAL puanlarının faktörlere göre dağılımı

Memnuniyet düzeyi en düşük olan ifadeler (konular) sıralandığında, ilk beş konu; "1- Son teknolojiye uygun, yeni donanım kullanımı", "15Üniversitede öğrencilerin, aldıkları eğitim hizmetlerine karşı güven duymaları", "6- Üniversite çalışanlarının, problem çözme konusunda samimi bir ilgi göstermeleri", "20- Üniversitede, tüm öğrencilerle ilgilenmeye yetecek sayıda çalışan bulunması", "14-Üniversite çalışanlarının, davranışlarıyla güven vermeleri" biçiminde sıralanmışlardır. "Son teknolojiye uygun, yeni donanım kullanımı" konusunda; Vakıf Üniversitelerinden daha fazla oranda beklenti söz konusu iken aynı konuya ilişkin algı daha düşük düzeyde Devlet Üniversiteleri için söz konusudur. "Üniversitede öğrencilerin, aldıkları eğitim hizmetlerine karşı güven duymaları" konusunda, Vakıf Üniversitelerinin, Devlet Üniversitelerine göre daha fazla beklenti ve daha az algı düzeyinde oldukları 
gözlemlenmiştir. Benzer gözlem "6-Üniversite çalışanlarının, problem çözme konusunda samimi bir ilgi göstermeleri" ifadesi için de geçerlidir. Bunlarla beraber, "14- Üniversite çalışanlarının, davranışlarıyla güven vermeleri" konusunda Devlet Üniversitelerinin nispeten daha az oranda memnuniyet oluşturabildiği de söylenebilir (Tablo 6).

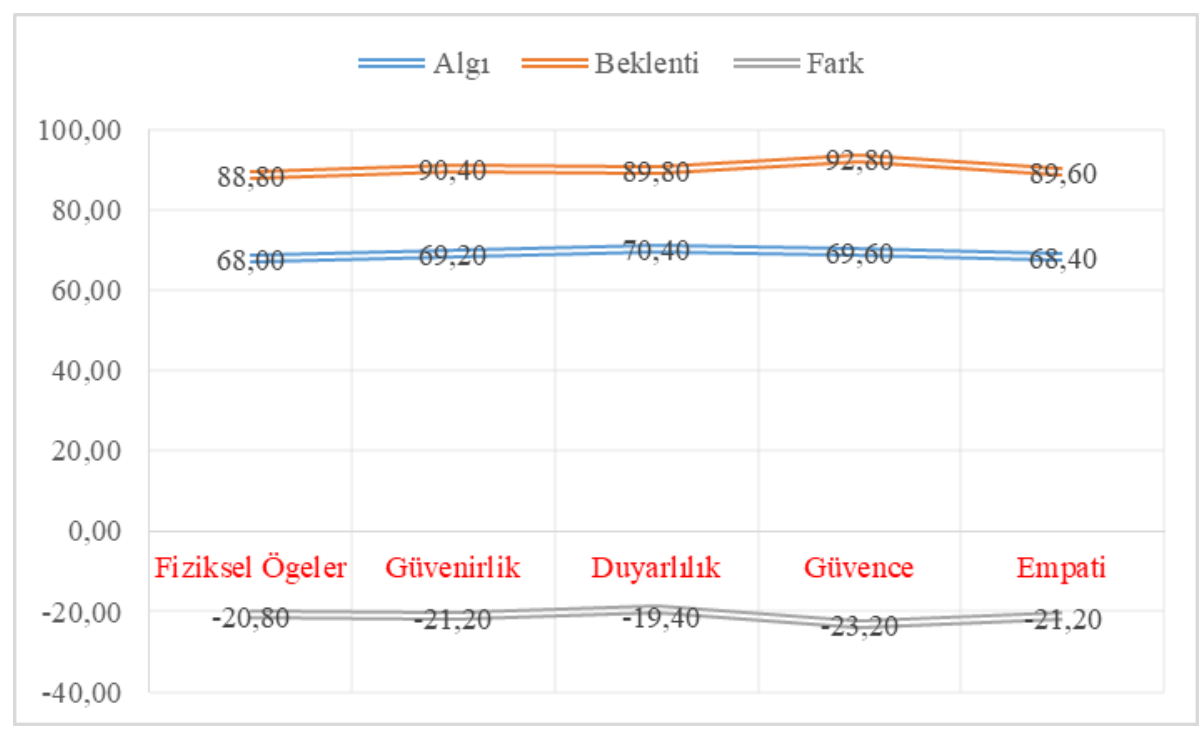

Şekil 4. Algı, Beklenti ve SERVQUAL puanlarının faktörlere göre yüzdelik dağılımı

Tablo 6. Memnuyet düzeyi en düşük olan ilk 5 ifadenin üniversite yapısına göre dağılımı

\begin{tabular}{|c|c|c|c|c|}
\hline İfadeler & Faktörü & Beklenti & Alg1 & Fark \\
\hline \multicolumn{5}{|l|}{ 1-Son teknolojiye uygun, yeni donanım kullanımı } \\
\hline Devlet Üniversitesi (\%84) & \multirow{3}{*}{ Fiziksel Ögeler } & 4,50 & 3,09 & $-1,41$ \\
\hline Vakıf Üniversitesi (\%16) & & 4,53 & 3,19 & $-1,33$ \\
\hline Ortalama & & 4,51 & 3,11 & $-1,40$ \\
\hline \multicolumn{5}{|c|}{ 15-Üniversitede öğrencilerin, aldıkları eğitim hizmetlerine karşı güven duymaları } \\
\hline Devlet Üniversitesi (\%84) & \multirow{3}{*}{ Güvence } & 4,64 & 3,40 & $-1,24$ \\
\hline Vakıf Üniversitesi (\%16) & & 4,79 & 3,33 & $-1,46$ \\
\hline Ortalama & & 4,66 & 3,39 & $-1,27$ \\
\hline \multicolumn{5}{|c|}{ 6-Üniversite çalısanlarını, problem çözme konusunda samimi bir iloi göstermeleri } \\
\hline Devlet Üniversitesi (\%84) & \multirow{3}{*}{ Güvenirlik } & 4,67 & 3,51 & $-1,16$ \\
\hline Vakıf Üniversitesi (\%16) & & 4,82 & 3,29 & $-1,53$ \\
\hline Ortalama & & 4,69 & 3,48 & $-1,21$ \\
\hline \multicolumn{5}{|c|}{ 20-Üniversitede, tüm öğrencilerle ilgilenmeye yetecek sayıda çalışan bulunması } \\
\hline Devlet Üniversitesi (\%84) & \multirow{2}{*}{ Empati } & 4,44 & 3,22 & $-1,22$ \\
\hline Vakıf Üniversitesi (\%16) & & 4,55 & 3,33 & $-1,22$ \\
\hline
\end{tabular}




\begin{tabular}{lrrrr}
$\begin{array}{l}\text { Ortalama } \\
\text { 14-Üniversite çalışanlarının, davranışlarıla güven vermeleri }\end{array}$ & 4,45 & 3,24 & $-1,21$ \\
Devlet Üniversitesi (\%84) & & 4,61 & 3,44 & $-1,16$ \\
Vakıf Üniversitesi (\%16) & Güvence & 4,79 & 3,51 & $-1,28$ \\
Ortalama & & 4,64 & 3,45 & $-1,19$ \\
\hline
\end{tabular}

\section{Sonuç ve Değerlendirme}

Hizmet kalitesi bir hizmet için en önemli özelliklerden ve gerekliliklerden birisidir. Öte yandan kaliteli hizmetin, "organizasyon genelinde ilham veren liderlikten" meydana geldiği (Kotler ve Keller, 2016, s.685) de ifade edilmelidir. Ayrıca yapılan araştırmalar sonucunda; piyasa yönelim derecesi ile müşteri memnuniyeti düzeyi, göreceli hizmet kalitesi, çalışanların örgütsel bağlılığı ve kârlılık arasında anlamlı ve pozitif yönlü ilişkiler olduğu ortaya konulmuştur. Bununla beraber, bir organizasyonda bir piyasa yönelimi benimsemenin üst yönetim özelliklerine (yönetim tarzı, liderlik, profesyonellik) bağlı olduğu da (Zairi, 1999, s.xxvi) ortaya konulmuştur. Dolayısıyla hizmet kalitesinin doğrudan yönetim tarzı ve etkinliği ile ilgili olduğu kabul edilebilir.

Araştırmadan elde edilen bulgulara göre: Devlet ve Vakıf Üniversitelerinin her ikisi için de, tüm alanlarda memnuyet düzeyinin düşük olduğu belirtilmelidir. Özellikle COVID-19 Pandemi sürecinde üniversitelerin uzaktan eğitim uygulaması ile beraber teknolojik altyapı ve donanımlarının önem kazandığı açıkça bilinmektedir. Buna ragmen genel olarak, en yüksek düzeyli memnuniyetsizliğin de bu hususta (Son teknolojiye uygun, yeni donanım kullanımı) olduğu gözlemlenmiştir. Öte yandan yine Pandemi döneminde önemi (beklenti düzeyi) -geçici olarak- tedricen azalmış gibi algılandığı, fiziksel alanların (binaların) yeterliliğine ilişkin memnuniyetsizlik (Binaların çağdaş bir görünüme sahip olması), en düşük oranda gerçekleşmiştir. Ancak bu alg1 ve durumun yanıltıcı olabileceği, eğitimin normal akışına dönmesi ile beraber, daha fazla kapalı alanların gereksinimi nedeni ile bu alanda büyük aksaklıkların olabileceği düşünülmektedir. Çünkü, Pandemi dönemi öncesinde olduğu gibi kalabalık, yoğun ve ferah olmayan, insan kullanımına yönelik her türlü kapalı alanların, Pandemi sonrasında bu şekilde kullanılamayacağı ya da kullanılmaması gerekliliği, öncelikle ve özellikle ifade edilmelidir. Dolayısıyla, tüm donanımların teknolojik 
gelişmişlik düzeyinin azami ölçüde artırılması ile birlikte, yapıların ve kapalı alanların genişletilmesi, ferahlaştırılması, insan yoğunluğunun seyreltilmesi ve teknolojik gelişmişlik düzeylerinin (eğitim faaliyetlerinin etkin ve verimliliğine, salgınlar, afet ve deprem riskleri, acil tahliye durumlarına yönelik biçimde) spesifik olarak yeniden tasarlanmaları ve/veya bu niteliklere sahip yeni binaların yapılması, öncül gerek ve şart olarak görülmektedir.

"Güvence" faktörü üniversite eğitim hizmetlerinin en önemli eksikliği ve memnuyetsizlik alanı olarak öne çımaktadır. "Güvenirlik", “Empati” ve "Fiziksel Ögeler" faktörleri de menfi olarak sıralanmışlardır. Nispeten en düşük oranda memnuniyetsizlik "Duyarlılık" ile ilgili konulardır. Bir başka ifade ile insanlar aldıkları eğitime güven duymamakta, empatik davranış karakteristiğine sahip yönetim anlayışının olmadığına ve üniversitelerin yeterli düzeyde teknoloji ve donanıma sahip olmadıklarını düşünmektedirler.

Vakıf üniversiteleri için en önde gelen memnuniyetsizlik alanları; "çalışanların, problem çözme konusunda samimi ilgi görmemeleri", "eğitim hizmetlerine duyulan güvensizlik" ve "çalışanların, davranışlarıyla güven vermemeleri" ile ilgili olduğu; buna karşın Devlet Üniversiteleri için en fazla memnuniyetsizlik alanlarının; "son teknolojiye uygun, yeni donanım kullanımı", "eğitim hizmetlerine duyulan güvensizlik", ve "yatersiz çalışan sayısı" ile ilgili olduğu söylenebilir.

Eğitim hizmetlerinin kalitesi ve niteliği, her alanda; kişiler için olduğu kadar toplumlar için de, geleceklerini ve yönlerini belirleyen en önemli faktör olarak ifade edilebilir. Öte yandan hizmet kalitesi, doğrudan yönetim etkinliği ve süreci ile ilgili bir sonuç olarak ortaya çıkmaktadır (Kotler ve Keller, 2016, s.685). Dolayısıyla araştırma bulgularına göre, hem Devlet hem de Vakıf Üniversite yönetimlerinin, COVID-19 Pandemi sürecinde etkin bir yönetim tarzı ve becerisi gösterememiş oldukları en göze çarpan, başlıca sonuçtur. Bu sonuç ışığında; Devlet ve Vakıf Üniversite yönetimlerinin sadece COVID-19 dönem şartlarını değil, dönem sonrası kalıcı gereklilik ve şartları da göz önünde bulundurarak (Doğan, 2021), fiziki ögelerinin (binalar ve teknolojik donanımlar başta olmak üzere) nitelik ve niceliklerini yukarı seviyelere ulaştırmaları tavsiye edilebilir. Yönetime katılım, empati, katılımcı liderlik tarzı, vizyoner yönetim, özellikle idari çalışanların eğitim, nicelik ve niteliklerinin 
artırılması, mezun kişilerin aidiyetlerinin oluşturulması ve çağdaş yönetim yaklaşımlarının uygulanmasının yararlı olabileceği söylenebilir. Genel olarak, üniversite dışı yönetim tecrübesi ile birlikte yönetim ile ilgili akademik birikimi olan kişilerin yönetimde rol almalarının yararlar sağlayabileceği düşünülmektedir.

Literatür incelemelerine göre, Türk Devlet ve Vakıf Üniversitelerinin hizmet değerlendirmesine ilişkin; bölgesel, yerel ya da tekil olmayan, kapsayıcı nitelikte çalışmalar bulunmamaktadır. Bu sebeple özellikle araştırmacılar ve akademisyenler için bu konuya ilişkin tek bir üniversiteden ziyade kapsayıcı ve tümevarım sonuçlara ulaşılabilen araştırmaların yapılması, bu araştırmaların COVID-19 Pandemi dönemi ve sonrası için değişimlerin ve beklentilerin ortaya konulması önemli görülmekte ve tavsiye edilmektedir. Yükseköğrenim ile ilgili üst kuruluşlar, bu çalışmada yapılan araştırmaya benzer, tüm üniversiteler için yıllık periyodlarla bir "hizmet kalite indeksi" ve sıralaması yapmalarının da yararlı olabileceği düşünülmektedir.

Günümüzde üniversite başarılarının, ağırlıklı olarak "yayın sayıları" temelinde değerlendirilme eğilimi gözlemlenmektedir, oysa yayın sayılarının niteliği ve niceliği üniversite yönetimlerinden ziyade akademik çalışanların daha çok bireysel faaliyetleri ile ilgili bir göstergedir ve bu konuda üniversite yönetimlerin desteği son derece kısıtlıdır. Ayrıca bir üniversitenin başarısı sadece yıllık yayın sayısından ibaret değildir. Dolayısıyla, üniversite yönetim etkinliğini belirlemek üzere; sosyal, ekonomik, eğitim ve akademik kriterlerin tamamı dikkate alınmalıdır. Söz konusu bu kriterler içinde hizmet kalite düzeyinin belirlenmesinin son derece önemli olduğu düşünülmektedir.

Üniversite okuyan ya da okumak üzere bir üniversite tercihinde bulunmak durumunda olan kişilere yönelik olarak; hizmet kalite düzeyinin dikkate alınması, hizmetin zayıf ve güçlü yönlerinin incelenmesi, karar süreçlerine eğitim hizmeti kalite sıralamasının dahil edilmesi, özellikle "verilen eğitimin güvenirliğine" ilişkin memnuniyet düzeyi başta olmak üzere diğer tüm hizmet alanları ile ilgili hususlara dikkat etmeleri önerilebilir. 
EXTENDED ABSTRACT

\section{A Research to Determine the Service Quality Levels of Turkish Universities in the COVID-19 Pandemic Process \\ * \\ Alpaslan Alpaslanoğlu \\ I ̆gdır University}

The COVID-19 Pandemic is putting educational institutions and administrations to tough tests, as in all areas of human civilization. It is thought that one of the most important indicators regarding the performance of university administrations during this challenging test period is the level of service satisfaction and the level of meeting stakeholder expectations. From this point of view, while representing the problem of the research of the effectiveness of the management behaviors shown during the COVID-19 Pandemic period, the determination of the level of satisfaction as a result of the management behaviors that the university administrations have shown so far during the pandemic process and the search for optimal management practices are the main reasons of this research. constitutes its purpose. Reasons for the research; During the COVID-19 Pandemic period, expectations for the organization and which organizational assets are considered more important, and in all areas, especially university administrations; It is the search for answers to whether more effective management behaviors can be shown during the COVID-19 Pandemic period. Research findings; It is thought that the COVID-19 Pandemic period may be important for the development of more effective management behaviors in post-period and extraordinary or unpredictable situations. On the other hand, it is thought that more effective applications can be put forward as a result of comparisons of values that can be obtained from other fields and sectors with similar methods and management behaviors for the COVID-19 Pandemic process. On the other hand, during the COVID-19 Pandemic period, which can be considered as an exceptional time period in human history, it is considered 
important because of the expectation that it can be a touchstone research to determine the level of university service quality.

Service Service quality is one of the most important features and requirements for a service. In addition, as a result of the research; It has been revealed that there are significant and positive relationships between the degree of market orientation and the level of customer satisfaction, relative service quality, organizational commitment of employees and profitability. Therefore, it can be accepted that service quality is directly related to management style and effectiveness.

According to the findings of the research: It should be noted that the satisfaction level is low in all areas for both State and Foundation Universities. It is clearly known that the technological infrastructure and equipment of the universities, together with the distance education application, especially during the COVID-19 Pandemic process. In general, however, it was observed that the highest level of dissatisfaction was also in this regard (the use of new equipment in accordance with the latest technology). On the other hand, dissatisfaction with the adequacy of physical spaces (buildings) (buildings have a contemporary appearance), whose importance (expectation level) was perceived astemporarily- gradually decreased during the Pandemic period, was at the lowest rate. However, it is thought that this perception and situation may be misleading, and with the return of education to its normal flow, there may be major disruptions in this area due to the need for more closed areas. Because, as before the Pandemic period, all kinds of closed areas for human use, which are not crowded, dense and spacious, cannot or should not be used in this way after the Pandemic, it should be expressed first and foremost. Therefore, with the maximum increase in the technological development level of all equipment, the expansion and refreshment of buildings and closed areas, the dilution of human density and the level of technological development (for the effectiveness and efficiency of educational activities, epidemics, disaster and earthquake risks, emergency evacuation situations). Specific redesigns and/or construction of new buildings with these qualities are seen as prerequisites and conditions. The "assurance" factor stands out as the most important deficiency of university education services and the area of dissatisfaction. "Reliability", "Empathy" and "Physical Components" 
factors are also listed as negative. The relatively lowest rate of dissatisfaction is related to "Sensitivity". In other words, people do not trust the education they receive, they think that there is no management understanding with empathic behavior characteristics and that universities do not have sufficient technology and equipment.

The leading areas of dissatisfaction for foundation universities are; It is related to "employees not showing sincere interest in problem solving", "distrust in education services" and "employees not giving confidence with their behavior"; On the other hand, the areas of greatest dissatisfaction for State Universities are; It can be said that it is related to "use of new equipment suitable for the latest technology", "distrust in education services" and "number of incompetent employees".

The quality and quality of education services, in every field; It can be expressed as the most important factor determining their future and direction for societies as well as individuals. On the other hand, service quality emerges as a result directly related to management efficiency and process. Therefore, according to the research findings, it is the most striking and primary result that both State and Foundation University administrations have not been able to demonstrate an effective management style and skill during the COVID-19 Pandemic process. In the light of this result; It can be recommended that State and Foundation University administrations raise the quality and quantity of their physical elements (especially buildings and technological equipment) to higher levels, taking into account not only the COVID-19 term conditions, but also the permanent requirements and conditions after the term. It can be said that participation in management, empathy, participatory leadership style, visionary management, increasing the education, quantity and qualifications of especially administrative staff, creating the belonging of graduates and applying modern management approaches can be beneficial. In general, it is thought that people with non-university management experience and academic background in management can benefit from taking a role in management.

According to the literature review, regarding the service evaluation of Turkish State and Foundation Universities; There are no regional, local or non-singular, inclusive studies. For this reason, it is considered important and recommended for researchers and academics to conduct 
inclusive and inductive studies on this subject rather than a single university, and to reveal the changes and expectations of these researches for the COVID-19 Pandemic period and after. It is thought that it may be beneficial for higher education institutions to make a "service quality index" and ranking for all universities on an annual basis, similar to the research conducted in this study.

\section{Kaynakça / References}

American Society for Quality. (t.y.). Benefits of total quality management. 01.05.2021 tarihinde https://asq.org/quality-resources/total-qualitymanagement/tgm-gets-results adresinden erişildi.

Armstrong, G., Kotler, P., Trifts, V. ve Buchwitz, L. A. (2017). Marketing: An introduction. Toronto: Pearson.

Berry, L. L., Parasuraman, A. ve Zeithaml, V.A. (1988). The service quality puzzle. Business Horizon, 31(5), 35-43.

Bitner, M. J. ve Hubbert, A. R. (1994). Encounter satisfaction versus overall satisfaction versus quality: The customer's voice. R. T. Rust ve R. L. Oliver, (Der.), Service quality: New directions in theory and practice. Içinde (s.72-94) Thousand Oaks, CA: Sage.

Chartered Quality Professional ve International Register of Certificated Auditors. (2021). About quality. 01.05.2021 tarihinde https://wwww.quality.org/what-quality adresinden erişildi.

Deming, W. E. (2019). Krizden çıkış. (C. Akaş, Çev.). İstanbul: Kalder Yayın. (Orijinal eserin yayın tarihi 2000).

Doğan, A. (2021). The effects of COVID-19 Pandemic on business areas and post covid-19 management trends. Turkish Studies-Social, 16(1), 131156. https://dx.doi.org/10.47356.

European University Association. (2021). Covid-19 \& universities. 16.06.2021 tarihinde https:/leua.eu/issues/27:covid-19-and-universities-ineurope.html adresinden erişildi.

Fonseca, L., Amaral, A. ve Oliveira, J. (2021). Quality 4.0: The EFQM 2020 Model and Industry 4.0 relationships and implications. Sustainability, 13, 3107. https://doi.org/10.3390/su13063107.

Food and Agriculture Organization of the United Nations. (t.y.). What is quality?

01.05.2021 tarihinde http://wwww.fao.org/3/W7295E/w7295e03.htm adresinden erişildi. 
Güriş, S. ve Astar, M. (2014). Bilimsel araştırmalarda SPSS ile istatistik. İstanbul: Der Yayınları.

International Association of Universities. (2021). COVID-19 impact on higher education: Institutional and students' perspectives. 16.06.2021 tarihinde https://www.iau-aiu.net/IMG/pdf/joint paper iau and esn institutional and students perspectives of covid19 impact on higher education.pdf adresinden erişilmiştir.

International Trade Centre. (2011). Export quality management: A guide for small and medium-sized exporters. 2th Ed. World Trade Organization and the United Nations.

Kotler, P. ve Armstrong, G. (2018) Principles of marketing. 17th Ed. Harlow, UK: Pearson Education Limited.

Kotler, P. ve Keller, K. L. (2016). Marketing management. 15 Ed. Pearson India Education Services Pvt. Ltd.

Kotler, P., Armstrong, G., Harris, L. C. ve He, H. (2020). Principles of marketing. Eight European edition published. Harlow, UK: Pearson Education Limited.

Marinoni, G., Land, H. van't. ve Jensen, T. (2020). The impact of COVID-19 on higher education around the world, IAU global survey report. Paris: International Association of Universities (IAU)/UNESCO House.

Organisation for Economic Co-operation and Development. (2006). Glossary of statistical terms. 01.05.2021 tarihinde https://stats.oecd.org/glossary/detail.asp?ID $=5150$ adresinden erişildi.

Özdemir, A. (2019). Yönetim Biliminde ileri araştırma yöntemleri ve uygulamalar. 5. Baskı. İstanbul: Beta.

Parasuraman, A., Zeithaml, V. A. ve Berry, L. L. (1985). A conceptual model of service quality and its implications for future research. Journal of Marketing, 49(4), 41-50.

Parasuraman, A., Zeithaml, V. A. ve Berry, L. L. (1988). SERVQUAL: A multiple-item scale for measuring consumer perceptions of service quality. Journal of Retail, 64(1), 12-40.

Parasuraman, A., Berry, L. L. ve Zeithaml, V.A. (1991). Refinement and reassessment of SERVQUAL Scale. Journal of Retail, 67, 420-450.

Parasuraman, A., Zeithaml, V. A. ve Berry, L. L. (1994a). Reassessment of expectations as a comparison in measuring service quality: Implications for further research. Journal of Marketing, 58(1), 111-124. 
Parasuraman, A., Zeithaml, V. A. ve Berry, L. L. (1994b). Alternative scales for measuring service quality: A comparative assessment based on psychometric and diagnostic criteria. Journal of Retail, 70(3), 201-230.

Qiu, R. G. (2014). Service science the foundations of service engineering and management. Hoboken, New Jersey: John Wiley \& Sons, Inc.

QualityWBT Center for Education. (2017). ISO 9001:2015 Requirements from A to Z16, desk reference. 01.05.2021 tarihinde https://www.qualitywbt.org/FlexTraining/file/R39-QMS2015/ISO \%209001\%202015\%20Requirements $\% 20$ A 20 to \%20Z\%20De sk\%20Reference $\% 20 J P 07 \% 20$ Final2.pdf adresinden erişilmiştir.

Skinner, S. J. (1990). Marketing. Boston: Houghton Mifflin Company.

Zairi, M. (Ed.). (1999). Best practice process innovation management. Oxford: Buttenvorth-Heinemann.

Zeithaml, V. A., Berry, L. L. ve Parasuraman, A. (1996). The Behavioral Consequences of Service Quality. Journal of Marketing, 60, 31-46.

\section{Kaynakça Bilgisi / Citation Information}

Alpaslanoğlu, A. (2021). COVID-19 Pandemi sürecinde, Türk Üniversitelerinin hizmet kalite düzeylerini belirlemeye yönelik bir araştırma. OPUS-Uluslararası Toplum Araştırmaları Dergisi, 18(43), 65076529. DOI: 10.26466/opus. 944561. 